\title{
Boronate Oligomers via Dehydrogenation of Diols with Thexylborane
}

\author{
Yoshiki Chujo*, Ikuyoshi Tomita, and Takeo SAEgusa \\ Department of Synthetic Chemistry, Faculty of Engineering, Kyoto University, \\ Yoshida, Sakyo-ku, Kyoto 606, Japan
}

(Received August 27, 1990)

\begin{abstract}
As a series of our studies on novel boron-containing polymers, dehydrogenation reaction between bifunctional hydroborane compounds, i.e., thexylborane (1) and diols to produce a novel boronate oligomer is described here. When 1 was reacted with an equimolar amount of 1,6-hexanediol at room temperature for 1 day, a colorless wax was obtained after removing the solvent. The cryoscopic measurement of the molecular weight of the obtained wax indicated the formation of oligomeric species. This oligomer was purified by coagulation with $n$-pentane, and characterized by spectroscopic analyses. The thermal stability of the resulting boronate oligomer is also described.
\end{abstract}

KEY WORDS Boronate Oligomer/Dehydrogenation/Diol/ Thexylborane/ Boron-Containing Oligomer /

Boron compounds are widely used as a catalyst of polymerization, and as a crosslinking agent of phenolic compounds, poly(vinyl alcohol), and epoxy resin systems. ${ }^{1}$ However, there are few polymers consisting of boron atoms in the main chain, except for borazine, phosphinoborane, and decarborane polymers. ${ }^{2}$ Previously, the borate polymer was produced by the dehydration reaction of tetrahydroxydiphenyl with boric acid. ${ }^{2}$ In this system, the number of functionality of monomers was three or four. The obtained polymer was reported to be partly soluble in $\mathrm{N}, \mathrm{N}$-dimethylacetamide and showed heatresistant property.

Very recently, we reported hydroboration polymerization $^{3}$ and haloboration polymerization $^{4}$ as novel methodologies for the preparation of organoboron polymers, which showed interesting characteristics as reactive polymers. Here we wish to report soluble boronate oligomers prepared by the dehydrogenation reaction of diols with thexylborane.

\section{RESULTS AND DISCUSSION}

It is known that boron-hydride is readily substituted by the treatment with alcohols or phenols to produce the corresponding esters of boronic acid. ${ }^{5}$ This reaction can be used for the analysis of $\mathrm{B}-\mathrm{H}$ species, due to its quantitative conversion. ${ }^{5 \mathrm{~b}}$ Thus, bifunctional thexylborane (1) was employed as a monomer, and dehydrogenation between diols and 1 to produce a poly(boronic ester) was examined (Scheme 1).

Polymerization condition was examined by using 1 and 1,6-hexanediol (2a) (Table I). When 1 was reacted with one equivalent of $2 \mathbf{a}$ at room temperature for one day, colorless semi-solid was obtained in $94 \%$ yield after evaporating the solvent. Generally, boronic esters are known to be unstable toward moisture. The obtained oligomer in this study was also

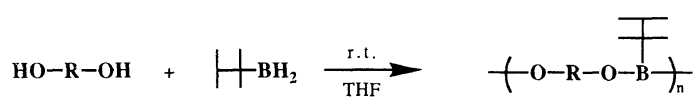

Scheme 1. 
Table I. Polymerization conditions

\begin{tabular}{|c|c|c|c|c|}
\hline \multirow[b]{2}{*}{ Run } & \multirow[b]{2}{*}{ Diols } & \multirow[b]{2}{*}{ Conditions } & Yield & \multirow[b]{2}{*}{ M.W. ${ }^{a}$} \\
\hline & & & $\%$ & \\
\hline 1 & $\mathrm{HO}\left(\mathrm{CH}_{2}\right)_{6} \mathrm{OH}(\mathbf{2 a})$ & r.t. ${ }^{\mathrm{g}} 1$ day & 94 & 600 \\
\hline 2 & & & $79^{c}$ & 1000 \\
\hline 3 & & & $9^{d}$ & 210 \\
\hline 4 & & reflux $4 \mathrm{~h}$ & $43^{e}$ & 1100 \\
\hline 5 & & r.t.1 day ${ }^{\mathbf{b}}$ & $88^{\mathrm{e}}$ & 1200 \\
\hline 6 & $\mathrm{HO}\left(\mathrm{CH}_{2}\right)_{2} \mathrm{OH}$ & r.t. 1 day & - & $150\left(156^{\mathrm{f}}\right)$ \\
\hline
\end{tabular}

a From cryoscopy (dry dioxane, under $\mathrm{N}_{2}$ ).

b $15 \%$ excess Thexylborane was used for the reaction.

c $n$-Pentane-soluble part of run 1 .

d $n$-Pentane-insoluble part of run 1 .

e $n$-Pentane-soluble part.

f Calculated value for a cyclic compound.

g r.t., room temperature.

decomposed under air (vide infra). Due to this instability, the molecular weight could not be estimated exactly by means of GPC even upon nitrogen bubbling. ${ }^{3}$ Thus, the molecular weight of the obtained oligomer was measured by a cryoscopic method under nitrogen, and was found to be 600 (run 1).

Purification of the obtained oligomer was carried out by coagulation with $n$-pentane under nitrogen. As shown in runs 2 and 3 in Table I, the molecular weight of the $n$-pentanesoluble part (3a) was higher than that of $n$ pentane-insoluble part. This may be explained by assuming the contaminated low molecular weight oligomers with unreacted hydroxyl group at the end, which are more polar and are insoluble in $n$-pentane. The low molecular weight estimated by cryoscopy might be due to some impurities which are soluble in $n$-pentane.

From the result of IR spectrum of $\mathbf{3 a}$, the conversion of $\mathbf{B}-\mathbf{H}$ group was found to be completed, while a small amount of unreacted hydroxyl group was observed. In ${ }^{1} \mathrm{H}$ NMR, however, the full characterization of the structure of 3a was disturbed by its instability. Although a peak around $3.46-4.26 \mathrm{ppm}$ assignable to the protons of methylenes adjacent
Table II. Dehydrogenation polymerization of various diols

\begin{tabular}{|c|c|c|c|c|c|}
\hline Run & Diols & & Conditions & $\begin{array}{c}\text { Yield } \\
\%\end{array}$ & $M . W .^{a}$ \\
\hline 1 & $\mathrm{HO}\left(\mathrm{CH}_{2}\right)_{6} \mathrm{OH}$ & (2a) & r.t. 1 day & $79^{b}$ & 1000 \\
\hline 2 & $\mathrm{HO}\left(\mathrm{CH}_{2}\right)_{8} \mathrm{OH}$ & (2b) & r.t. 1 day & $49^{b}$ & 1000 \\
\hline 3 & $\mathrm{HO}\left(\mathrm{CH}_{2}\right)_{12} \mathrm{OH}$ & (2c) & r.t. 1 day & $52^{b}$ & 1100 \\
\hline 4 & Hydroquinone & (2d) & r.t. 1 day & $100^{\mathrm{c}}$ & - \\
\hline 5 & Bisphenol-A & (2e) & r.t. 1 day & $56^{\mathrm{b}}$ & 700 \\
\hline
\end{tabular}

a From cryoscopy (dry dioxane, under $\mathrm{N}_{2}$ ).

${ }^{\mathrm{b}} n$-Pentane soluble part.

c This polymer became insoluble during work up.

to boronic ester was observed, the integral ratio of protons of thexyl group to those of inner methylenes was somewhat lower $(71 \%)$ than the calculated value for the expected structure. From this value, the molecular weight was calculated to be 640 by assuming that the terminal unit was derived from diol.

When polymerization was carried out under tetrahydrofuran (THF) reflux condition, the corresponding oligomer having the molecular weight of 1100 was isolated in $43 \%$ yield (run 4). On the other hand, when a small excess amount of 1 was reacted at room temperature, the oligomer $\left(M_{n}=1200\right)$ was isolated in $88 \%$ (run 5).

Various diols were subjected to this polymerization with an equimolar amount of $\mathbf{1}$ at room temperature (Table II). Diols such as 1,8-octanediol (2d), and 1,12-dodecanediol (2c), and also bisphenol-A (2e) produced the corresponding oligomers like $\mathbf{2 a}$. The oligomer from 1 and hydroquinone (2d), however, became insoluble during the treatment with $n$-pentane.

The stability of 3a against water was monitored by ${ }^{1} \mathrm{H}$ NMR. When a $\mathrm{CDCl}_{3}$ solution of $3 a$ was shaken with $\mathrm{D}_{2} \mathrm{O}$ in a test tube at room temperature, the peak around $3.46-4.26 \mathrm{ppm}\left(-\mathrm{CH}_{2}-\mathrm{OB}\right)$ was found to be shifted to higher field $\left(3.23-4.07 \mathrm{ppm},-\mathrm{CH}_{2}-\right.$ OD). ${ }^{6}$ This result means that $\mathbf{3 a}$ is readily decomposed by water, as is usual for boronic 


\section{Boronate Oligomers via Dehydrogenation}

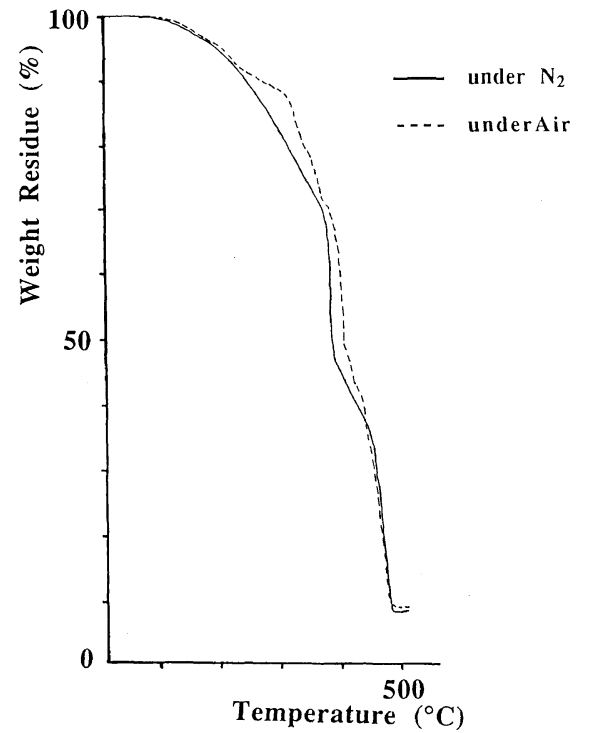

Figure 1. Thermogravimetric analysis of 3a.

esters. $^{7}$

Thermogravimetric analysis of $\mathbf{3 a}$ wás carried out under nitrogen stream or under air. As is shown in Figure 1, in both cases, the weight loss started at $100^{\circ} \mathrm{C}$, and was completed at $480^{\circ} \mathrm{C}$ to give $8 \%$ of residue.

The oligomers prepared in this study have low stability toward moisture. Nevertheless, unique characters and reactivities may be derived from the structures of boronic esters, which must be the next target in our group.

\section{EXPERIMENTAL}

\section{Materials and Instruments}

1 was prepared by the reaction of boraneTHF complex and 2,3-dimethyl-2-butene ${ }^{8}$ as reported earlier, and was purified by distillation $^{3}\left(48-49^{\circ} \mathrm{C} / 0.1 \mathrm{mmHg}\right)$. Tetrahydrofuran and $n$-pentane were dried over lithium aluminum hydride and distilled before use. 1,4-Dioxane was dried over sodium and distilled before use. $\mathbf{2 a}-\mathbf{2 c}$ were purified by distillation. 2d and $2 \mathbf{e}$ were recrystallized from benzene and from diethyl ether/ligroin, respectively.
${ }^{1} \mathrm{H}$ NMR spectrum was recorded in $\mathrm{CDCl}_{3}$ on a Hitachi R-600 $(60 \mathrm{MHz})$ instrument. IR spectrum was obtained on a Hitachi 260-50 spectrometer. Thermogravimetric analysis (TGA) was made on a Shimadzu DT-30 instrument $\left(15^{\circ} \mathrm{C} \mathrm{min}^{-1}\right)$ under air or nitrogen stream. Cryoscopic experiment was carried out under nitrogen atmosphere using dried 1,4dioxane as a solvent.

\section{Synthesis of Boronate Oligomers (3a)}

As a typical procedure, to a $2.0 \mathrm{M}$ THF solution of $2 \mathrm{a}(1.34 \mathrm{~g}, 11.3 \mathrm{mmol}), 1(1.11 \mathrm{~g}$, $11.3 \mathrm{mmol}$ ) was added at ambient temperature under nitrogen atmosphere. The reaction mixture was kept standing at room temperature for 1 day under nitrogen. Evaporation of the solvent gave a colorless gum in $94 \%$ yield ( $2.26 \mathrm{~g}, M_{n}=600$, from cryoscopy). When the obtained gum was washed with three $10 \mathrm{ml}$ portions of $n$-pentane, $9 \%$ of white solid remained undissolved $\left(M_{n}=210\right.$, from cryoscopy). The $n$-pentane-soluble part was corrected and was freeze-dried with dry 1,4dioxane to give $79 \%$ of $3 \mathbf{a}$ as a semi-solid $\left(M_{n}=1000\right.$, from cryoscopy). ${ }^{1} \mathrm{H} \operatorname{NMR}(\delta$, $\left.\mathrm{CDCl}_{3}\right) 0.53-1.02\left(-\mathrm{CH}_{3}\right), 1.08-1.98(-\mathrm{CH}$, $\left.-\mathrm{CH}_{2}-\right)$, and $3.86 \mathrm{ppm}\left(\mathrm{O}-\mathrm{CH}_{2}-\right.$, m); IR (neat) $2960,1468,1306,1180,1062 \mathrm{~cm}^{-1}$.

In a similar manner, $\mathbf{3 b}-\mathbf{3 e}$ were prepared. 3b (from $0.296 \mathrm{~g}, 3.02 \mathrm{mmol}$ of 1 and $0.438 \mathrm{~g}$, $3.00 \mathrm{mmol}$ of $2 \mathrm{~b})$ : yield $0.353 \mathrm{~g}(49 \%) ;{ }^{1} \mathrm{H}$ $\operatorname{NMR}\left(\delta, \mathrm{CDCl}_{3}\right) 0.50-1.03\left(-\mathrm{CH}_{3}\right), 1.06$ $2.14\left(-\mathrm{CH},-\mathrm{CH}_{2}-\right), 3.86\left(\mathrm{O}-\mathrm{CH}_{2}-, \mathrm{m}\right)$; IR (neat) 2910, 1460, 1312, 1290, 1160, 1040 $\mathrm{cm}^{-1}$. 3c (from $0.172 \mathrm{~g}, 1.76 \mathrm{mmol}$ of 1 and $0.354 \mathrm{~g}$, $1.75 \mathrm{mmol}$ of $2 \mathrm{c})$ : yield $0.267 \mathrm{~g}(52 \%) ;{ }^{1} \mathrm{H}$ NMR $\left(\delta, \mathrm{CDCl}_{3}\right) 0.53-1.03\left(-\mathrm{CH}_{3}\right), 1.06-2.18$ $\left(-\mathrm{CH},-\mathrm{CH}_{2}-\right), 3.89\left(\mathrm{O}-\mathrm{CH}_{2}-, \mathrm{m} 4 \mathrm{H}\right)$; IR (neat) 2920,1458, 1280,1164, $1056 \mathrm{~cm}^{-1}$. 3d (from $0.723 \mathrm{~g}, 7.37 \mathrm{mmol}$ of 1 and $0.805 \mathrm{~g}$, $7.31 \mathrm{mmol}$ of $\mathbf{2 d}$, without $n$-pentane treatment); ${ }^{1} \mathrm{H}$ NMR $\left(\delta, \mathrm{CDCl}_{3}\right) \quad 0.56-1.12 \quad\left(-\mathrm{CH}_{3}\right)$, $1.12-2.06\left(-\mathrm{CH}_{2}-\right), 6.38-7.02\left(\mathrm{C}_{6} \mathrm{H}_{4}\right)$; IR (in $\left.\mathrm{CHCl}_{3}\right)$ 2940, 1500, 1460, 1358, 1094, 900, 837 $\mathrm{cm}^{-1}$. 3e (from $0.208 \mathrm{~g}, 2.12 \mathrm{mmol}$ of 1 and 
$0.485 \mathrm{~g}, 2.13 \mathrm{mmol}$ of $2 \mathrm{e})$ : yield $0.382 \mathrm{~g}(56 \%)$;

${ }^{1} \mathrm{H}$ NMR $\left(\delta, \mathrm{CDCl}_{3}\right) \quad 0.50-1.08 \quad\left(-\mathrm{CH}_{3}\right)$, $1.08-2.04\left(-\mathrm{CH},-\mathrm{CH}_{2}-,-\mathrm{CH}_{3}\right), 6.42-7.31$ $\left(\mathrm{C}_{6} \mathrm{H}_{4}, \mathrm{~m}\right.$ ); IR (in $\mathrm{CHCl}_{3}$ ) 3320, 2950, 1604, $1460,1355,1080,904 \mathrm{~cm}^{-1}$.

\section{REFERENCES}

1. W. C. Teach, "Encyclopedia of Polymer Science and Technology," 2, 556 (1965).

2. W. C. Teach and J. Green, "Encyclopedia of Polymer Science and Techonology”, 2, 581 (1965).

3. Y. Chujo, I. Tomita, Y. Hashiguchi, H. Tanigawa, E. Ihara, and T. Saegusa, Macromolecules, 24. 345
(1991).

4. Y. Chujo, I. Tomita, and T. Saegusa, Macromolecules, 23, 687 (1990).

5. (a) H. C. Brown and S. K. Gupta, J. Am. Chem. Soc., 93, 1816(1971); (b) H. C. Brown, A. K. Mandal, and S. U. Kulkarni, J. Org. Chem., 42, 1392 (1977); (c) A. Pelter, K. Smith, and H. C. Brown, in "Borane Reagents"; Academic Press, London, 1988, p 434 and references cited therein.

6. For example, $(\text { EtO })_{3}$ B has a quartet peak at $\delta$ $3.83 \mathrm{ppm}$, while EtOH has the corresponding peak at $\delta 3.59 \mathrm{ppm}$.

7. A. Pelter, K. Smith, and H. C. Brown, in "Borane Reagents"; Academic Press, London, 1988.

8. H. C. Brown and E. Negishi, J. Am. Chem. Soc., 94, 3567 (1972). 